\title{
A Study on the Relationship between College Mathematics Teaching and Quality Education
}

\author{
Lingxia Huang \\ Teachers' College of Xi'an University, 710065
}

Keywords: College mathematics; Teaching; Quality education; Relationship; Study

\begin{abstract}
Education determines the basis for the formation of our comprehensive national strength. University education is the front end of higher education, and its educational results directly determine the strength of national strength. College mathematics is necessary to quality of many future laborers. This paper focuses on the relationship between college mathematics teaching, college mathematics teaching reform and quality education from the perspective of quality education. For the research on relationship between college mathematics teaching and quality education, the combination of introductory teaching, heuristic teaching and teaching model is generally advocated.
\end{abstract}

\section{Introduction}

Quality is the unique temperament of human. Quality education is a generic term of education that imparts knowledge and ability and enhances the level of intelligence. Quality education involves all aspects of people's thinking and moral quality and includes education on ideological quality, moral quality, scientific quality, psychological quality and physical quality. This series of quality education, under the premise of the rapid development of contemporary science and technology, is valued by the nation and education departments.

\section{The Importance of Quality Education in College Mathematics Teaching}

Well equipped youths lead to a powerful country. College mathematics teaching level indirectly affects the strength of national strength of China. Mathematics education is in a very basic stage during the formation of comprehensive national strength. With the very rapid development of knowledge economy today, talents experience fierce competition in the social economy. Enhancing the quality of talents is inevitable to make the college students meet the needs of social development. Understanding the relationship between college mathematics teaching and quality education, comprehensively cultivating students' innovative awareness and innovation ability, and helping college students step into the information age are the issues for every teacher of college mathematics to think in depth.

\section{The Fundamental Role of Quality Education}

Quality education is the basic content of introductory education. Even in the university, quality education is also the basic content for each university students to learn. It is very important to impart the necessary knowledge in the process of college mathematics teaching. However, learning knowledge must be based on the correct views of learning, values and outlook of life in order to achieve good teaching results, and thus students are able to apply the knowledge in the future. Therefore, at the beginning of college mathematics teaching, in order to help students successfully complete the transition from high school students to college and university students, we should first help students understand the purpose of comprehensive quality education such as moral, intellectual, physical, artistic, and labor education, and understand their role in the learning process and how to improve their overall quality. Teachers of college mathematics should understand the promotion effect of quality education on the college mathematics teaching. 


\section{The Relationship between College Mathematics Curriculum and Quality Education}

The college mathematics curriculum is closely related to the quality education. After understanding the purpose of study, the students should be clear about their future status and responsibility as the talents of higher education in the society, and they should not be ordinary. The students study hard in the school not only for personal growth, but also for their social responsibility. The quality education can comprehensively enhance the overall quality of students; it can not only enhance their emotional intelligence and IQ, but also guarantee the mathematics learning from the perspective of enhancing physical quality. Under the premise of effectively improving the comprehensive level of quality education, college mathematics teachers must let students understand the importance of learning higher mathematics. In the case of the rapid expansion of social data applications, mathematics is not only widely applied to the various disciplines of nature and engineering, but also involved in all aspects of social science, and even in the government administration and social daily application, mathematical thinking is a very important basis of knowledge. Therefore, to understand the interdisciplinary application between the college mathematics curriculum and quality education is important to measure the national culture quality.

\section{The Role of Quality Education in College Mathematics Teaching}

Due to the close connection between college mathematics education and quality education, it is necessary for students to use mathematical concepts in quantitative thinking, and on this basis, use the results of the quantitative thinking to carry out qualitative analysis. In the process of college mathematics education, teachers should actively exert the effect of quality education to achieve effective outcomes of higher mathematics education, broaden the students' view in mathematics, and enhance students' enthusiasm for learning mathematics, thus improving the comprehensive effect of college mathematics learning.

\section{Enhancing the Overall Teaching Quality of College Mathematics}

Quality education can play a good guiding role for college students in the stage of college teaching. In order to improve the overall teaching quality of college mathematics, the teachers should adopt a variety of teaching modes, and impart the methods and connotation of mathematics learning to students. Quality education can cultivate students' initiative and enthusiasm, and on the basis of respect for teachers, students can cooperate with the teacher to understand the expertise and ideas of solving problems. Quality education can lead students to think positively, enhance students' initiative in learning, and help students to develop good habits in learning mathematics. Only by spontaneously drawing inferences about other cases from one instance to closely connect the typical cases of college mathematics teaching and the values in the daily life, the students can be able to form a unique insight, and come up with a solution to specific issues, thus promoting the overall quality of college mathematics teaching.

\section{Improving the Overall Teaching Efficiency of College Mathematics}

Quality education is not only the education in the field of culture, knowledge and thought; physical education and psychological education are also the important contents of quality education. For students with good physical and psychological endurance, teachers can get twofold results with half the effort in the process of mathematics teaching. Students with higher quality can learn mathematics consciously. On this basis, teachers can transform different teaching models, and students can quickly grasp and absorb the specific content of mathematics imparted by the teachers, and closely follow the teacher's thinking and put forward some insightful questions. Even some students have strong mathematical thinking ability; they can not only independently complete the mathematical learning and practice and master the basic learning skills of college mathematics, but also discuss with the teacher, and cooperate with the teacher in carrying out deduction of some college mathematics projects while broadening their own knowledge base. 


\section{Promoting the Comprehensive Development and the Formation of Innovative Thinking of Students}

Mathematical thinking is derived from life and finally applied to the life. The college mathematics can not only provide the basis of the professional skill for the students majored in mathematical logic to help them enhance the specific capacity and skills in physics and chemistry, but also improve the overall mathematical thinking of Chinese university students, arouse their desire to learn mathematics and use mathematical thinking in the daily life to speed up the work efficiency. Therefore, in the process of college mathematics teaching, utilizing quality education can comprehensively promote the formation of innovative thinking of students. Under the premise of the reform of the new curriculum standards, innovative thinking and passionate learning are advocated by the education department. The quality education is needed to encourage students to keep strong thirst for knowledge and maintain a good learning attitude. College teachers in the process of quality education should pay great attention to the specific teaching cases to bring students into the process of mathematics learning by passionate lectures, avoiding to repeat what the book says to develop students' exploring spirit and enthusiasm for learning and their innovative thinking.

Making the College Mathematics Teaching More Ecologicalized, Dynamic and Effective

Due to the reform of modern mathematics teaching, college mathematics is not boring anymore. According to the principles of more ecologicalization and dynamic, the contents of college teaching and quality education are closely connected; utilizing the comprehensive quality teaching can make the college mathematics teaching not so boring, but become more vivid and interesting. Since the quality education involves many aspects, the students in the process of learning mathematics can use interdisciplinary learning methods to carry out discussion or develop multi-level learning patterns. For example, in the process of college mathematics teaching, we can use flip teaching to enable students to learn the mathematics autonomously, and use mathematical methods to solve practical problems. We can also combine mathematics and other disciplines to let students understand the specific application of mathematics in life and work.

\section{Analysis of Quality Education Strategies in College Mathematics Teaching}

With the correct learning methods and learning ability, the university students will not feel tired in the process of learning mathematics. In learning mathematics with highly abstract content, combining mathematical teaching methods and quality education strategies can effectively guide students to prepare lessons before class, study with the problems they encountered in the classroom, and discuss with teachers after class.

\section{Training Professional College Mathematics Teachers}

The college mathematics teachers with rich teaching experience are essential to develop better mathematics learning. Specialized college mathematics teachers should be able to master a wide variety of teaching methods. Throughout the teaching process, the role of teachers is very obvious and irreplaceable. University teachers should establish a series of feasible teaching methods in the perspective of educating, and according to the people-oriented teaching principles, understand the actual situation of students and how to teach according to circumstances. In addition, on-the-job training in the spare time should be encouraged to improve the teaching ability of teachers.

\section{Cultivating the Initiative and Enthusiasm of College Students in Mathematics Learning}

We should cultivate the initiative and enthusiasm of college students in mathematics learning, enabling them to understand the important role of mathematics in life and career, overcome the fear to mathematics learning, and use flexible and diverse learning tools and techniques to learn mathematics. Cultivating the initiative of college students in mathematics learning should be on the basis of innovation, using a variety of teaching methods to break down the bottleneck of traditional mathematics teaching. We should let students themselves realize that mathematics learning can promote the future study of other disciplines. At the same time, in the future self-employment or work, the basic ability of mathematics learning can bring huge profits for students themselves. 


\section{Establishing Heuristic and Exploratory Abstract Learning Model}

Due to the abstract nature of college mathematics, we must use the heuristic and exploratory abstract learning model to solve the problem of difficulty in math learning. For many students in high school, mathematics may be limited to solving basic problems; college mathematics is more abstract with more learning content. For some students majored in science, the research on mathematics may achieve the academic level. Therefore, we should use the heuristic learning methods to gradually guide students to lay a good foundation, and on this basis, help them establish adequate confidence in mathematics learning; then they can develop self-learning habits in the process of exploring, and continue to study mathematics with innovative thinking.

\section{Setting up a Variety of Elective Courses for College Mathematics Major from the Perspective of History}

The mathematics teaching and learning have a very long history. Therefore, teachers can, from the perspective of history, introduce the stories of famous mathematicians and their achievement in mathematics, so that students can understand the data as well as the story behind the data, and become interested in mathematics. Through combination with other humanistic courses, mathematics learning will become more interesting. This can not only enhance the confidence and ability of students in mathematics learning, but also help students to determine the approach to learn mathematics, and explore other ways to learn a large number of knowledge with mathematical characteristics, so as to improve their comprehensive ability.

\section{Developing School-based Compilation for College Mathematics and Quality Education through Combination with the Quality Education Aims}

On the basis of quality education, we should understand the specific learning situation of students and the basic situation of the school, then on this basis, compose school-based compilation suitable for students in their majors. In the process of composing school-based compilation, we need to combine with the specific requirements of quality education, add the successful teaching cases, keep pace with the times, and strictly follow the guidelines of college mathematics education, so that the teaching content will not be divorced from social development.

\section{Conclusion}

In summary, the college mathematics teaching and quality education cannot be separated. Quality education plays a very important role in the reform and development of college mathematics. In the process of college mathematics teaching, fully arousing the student's initiative and enthusiasm, cultivating the innovative thinking of students and their will to solve the problem independently are the necessary tasks of college mathematics teachers. University education is the process of spreading knowledge, and the process of ideological education and humane cultivation. In this regard, college mathematics teaching and quality education are unified. This is the primary task of mathematics teaching and the necessary standard to measure the success of mathematics teaching. Therefore, it is the common goal of future mathematics teaching and quality education to combine the mathematics teaching and quality education in the university to solve the problem and summarize experience from practice and cultivate high-quality talents.

\section{References}

[1] Wei L.L. Optimizing the Process of College Mathematics Teaching to Promote Quality Education [J]. Education for Chinese After-school,2016,(27):64+70.

[2] Liu J.R. Discussion and Practice of Humanistic Quality Education in College Mathematics Teaching [J]. New Curriculum Research,2015,(11):28-30.

[3] Jiang R., Zhou M. Some Ways to Improve the Quality of College Mathematics Teaching under the Background of Quality Education [J]. Journal of Southwest China Normal University, 2015, 40(04): 176-180.

[4] Lin Y.J. Research on Quality Education and Reform of College Mathematics Teaching [J]. Shuxue Xuexi Yu Yanjiu,2014,(23):9. 
[5] Li Y., Zou T.R. Brief Analysis on Mathematics Quality Education in Mathematics Teaching in Agricultural University [J]. Journal of Huanggang Normal University,2012,32(06):67-68.

[6] Liu Z.H. Brief Analysis on Quality Education in College Mathematics Teaching [J]. Journal of Guangxi University For Nationalities(Natural Science Edition),2012,18(03):100-102.

[7] Cheng X.M. The Necessity of Improving the Professional Quality of College Mathematics Teachers from the Perspective of Psychology [A]. Wuhan University, Scientific Research Publishing. Proceedings of Conference on Creative Education(CCE2012) [C].Wuhan University, Scientific Research Publishing:,2012:3.

[8] Tang Y.P. Carrying out the Teaching of Mathematics Experiment Course and Strengthening the Quality Education of College Mathematics [J]. China CIO News,2011,(06):149-150+160.

[9] Wu Z.P. Reflections on Quality Education and College Mathematics Teaching [J]. Journal of Tongling University,2010,9(02):114-115.

[10] Xu X.L., Du P. Brief Analysis on Quality Education and Reform of College Mathematics Teaching [J]. Decision and information (financial observation),2010,(10):124.

[11] Cheng W., Wang L.J. Exploring College Mathematics Teaching with the Idea of Quality Education [J]. Journal of Tianjin University of Light Industry,2003,(S1):108-109.

[12] Zhao C.K. The Mode Construction and Practical Exploration of the Teaching Method of Subjectivity in Senior High School [D]. Guangxi Normal University,2012. 